Review

\title{
Investigating the Integration of Industry 4.0 and Lean Principles on Supply Chain: A Multi-Perspective Systematic Literature Review
}

\author{
Mahsa Mahdavisharif*(D), Anna Corinna Cagliano (D) and Carlo Rafele
}

Citation: Mahdavisharif, M.; Cagliano, A.C.; Rafele, C. Investigating the Integration of Industry 4.0 and Lean Principles on Supply Chain: A Multi-Perspective Systematic Literature Review. Appl. Sci. 2022, 12, 586. https://doi.org/ 10.3390/app12020586

Academic Editor: Radu Godina

Received: 24 November 2021 Accepted: 25 December 2021 Published: 7 January 2022

Publisher's Note: MDPI stays neutral with regard to jurisdictional claims in published maps and institutional affiliations.

Copyright: (C) 2022 by the authors. Licensee MDPI, Basel, Switzerland. This article is an open access article distributed under the terms and conditions of the Creative Commons Attribution (CC BY) license (https:// creativecommons.org/licenses/by/ $4.0 /)$.
Department of Management and Production Engineering, Politecnico di Torino, Corso Duca Degli Abruzzi 24, 10129 Torino, Italy; anna.cagliano@polito.it (A.C.C.); carlo.rafele@polito.it (C.R.)

* Correspondence: mahsa.mahdavisharif@polito.it

\begin{abstract}
The development of digital technologies in all aspects of human life leads to increasing the necessity for investigating them in the Supply Chain (SC) as the main channel to provide products. Moreover, Lean principles, with the aim of reducing wastes, could be one of the main research streams in SC in recent years. Therefore, it is valuable to figure out the mutual effects of Lean principles and digital technologies as two growing areas in SC. Previous works did not pay attention to investigating this relationship at the SC level and were more focused on the production level. However, the present work addresses this issue by conducting a multi-perspective Systematic Literature Review (SLR). Additionally, in the present SLR, the impact of individual Industry 4.0 technologies in relation to Lean principles was investigated from various SC perspectives. The results reveal the necessity of studying single SC processes in Lean Digital SC. Moreover, the applicability of each technology should be illustrated to alleviate SC operational and organizational issues. The results provide useful insights about applying single digital technologies as well as a combination of them to each SC process to solve specific issues.
\end{abstract}

Keywords: Industry 4.0; Lean; digital technology; Supply Chain Management; Systematic Literature Review

\section{Introduction}

By increasing competitiveness to retain market share, SC members need to access realtime data about customer preferences and other SC information in a timely manner [1]. In this regard, Industry 4.0 technologies, such as Cloud Computing (CC), Big Data Analytics (BDA), Internet of Things (IoT), Blockchain (BC), and Additive Manufacturing (AM), can assist SC members to connect processes by making them able to exchange information quickly and safely. For instance, [2] mentioned the potential applicability of IoT for gathering real-time data and storing them in a transparent manner by BC. Moreover, they employ the advantages of BDA to analyze the collected data for optimizing vehicle routing and reducing carbon emissions. Additionally, BDA can help enhance marketing activities and provide a better perception of customer needs, which leads to efficient resource usage in manufacturing $[3,4]$. In addition, there is a mutual effect between applying Lean Manufacturing principles and Industry 4.0 technologies. As a matter of fact, Lean principles can pave the way for applying Industry 4.0 technologies, and digital practices can in turn support creating an operational environment with either zero or a limited amount of waste [5]. To this end, here Lean Digital Supply Chain (Lean DSC) is defined as a proper application of Industry 4.0 technologies in order to achieve Lean goals by reducing wastes in all SC echelons. Based on a classification by [6], there are seven types of wastes: transportation, inventory, motion, waiting, defect, over-production, over-processing. However, recently, under-utilized people are also considered as an eighth waste in the Lean principles [7]. 
However, the implementation of the different Industry 4.0 technologies together with the Lean principles is still a challenge for SC practitioners, and there is a need to have a clear roadmap and framework for applying them [8]. The present work aims to integrate the current state-of-the-art information about Lean Digital Supply Chain (DSC) by providing a broader perspective than the previous works, in order to assist both academicians in advancing theoretical outcomes on the topic and practitioners in real implementations. A Systematic Literature Review (SLR) is used to this end as a structured and scientific approach to identify and extract knowledge from the available contributions in a systematic way [9]. Previous SLRs mainly address the combined application of the Lean and Industry 4.0 notions to manufacturing as one of the SC echelons [10-13]. Thus, studies on the effects of Lean and digital technologies on all the main SC processes other than manufacturing are needed. Furthermore, the perspective of the different SC members should be taken into account because they may have heterogeneous attitudes and viewpoints regarding the applicability of Industry 4.0 technologies and Lean [14].

Aside from the mentioned research gap, previous SLRs mainly deal with the relationship between Lean principles and Industry 4.0 by considering the latter as a general concept without focusing on its detailed technologies. However, it should be pointed out that each individual Industry 4.0 technology has specific features making it applicable to either be compliant with or foster a Lean SC environment. Therefore, the present work, by studying single Industry 4.0 technologies at an SC level, aims to answer the following research questions:

(1) Which SC processes can benefit from an integrated application of Lean and digital technologies?

(2) Which Industry 4.0 technologies have the greatest potential to be combined with Lean principles in the main operational and organizational SC issues?

(3) Which Industry 4.0 technologies can be jointly applied in order to support Lean principles in the SC?

The results of the present work show the importance of investigating single processes in Lean DSC. Additionally, aside from focusing on information sharing as the main benefit of Lean DSC, researchers should apply Industry 4.0 technologies to enhance the other operational and organizational issues such as scheduling financial, risk assessment, etc. Moreover, CC, IoT, BDA are identified as the basic Industry 4.0 technologies to implement in Lean DSC. The rest of the paper is organized as follows: In Section 2 research background is presented. In Section 3, the selecting of keywords in different levels and also each perspective will be motivated. Then, in Section 4 the results of classification and main outcomes of the SLR will be discussed. Finally, Section 5 concludes the main points of the paper, implications and asserts the limitations regarding the present work.

\section{Research Background}

Nowadays, the accelerated diffusion of digital technologies reveals the importance of studying their effects on SCs [15]. Moreover, SC integration can result in more competitiveness and higher performance. Better integration and monitoring of SC processes by exploiting the digital paradigm enable the reduction of waste and achieve continuous improvement as suggested by the Lean principles [16]. The results of a survey by [17] indicated the inclination of SC members to know about the mutual effects of applying both Lean and digital technologies in SC. Moreover, Lean principles can provide a proper condition to implement Industry 4.0 technologies to increase process efficiency $[17,18]$. Furthermore, real-time data provided by Industry 4.0 can assist to use Lean principles in SCs [19]. As a result of the relationship that can be hypothesized between Industry 4.0 and Lean Manufacturing, previous research argued that the compatibility of the two notions should be investigated in more detail. In fact, understanding how and when Lean principles and digital technologies can be combined together is a strategic decision for the SC members $[17,20]$. 
At the first step, identifying and determining the definition of different Industry 4.0 technologies can help to have a better perception of them. Therefore, Table 1 describes the definition of all digital technologies that were included in the Industry 4.0 concept.

Table 1. Definition of Industry 4.0 technologies.

\begin{tabular}{|c|c|c|}
\hline Industry 4.0 Technology & Definition & Reference \\
\hline Augmented Reality (AR) & $\begin{array}{l}\text { AR is a potential technology to assist employees } \\
\text { by enlarging the real world by providing } \\
\text { additional information from different sources } \\
\text { and types such as text, video, sound, and even } \\
\text { smell. }\end{array}$ & {$[21,22]$} \\
\hline Cloud Computing(CC) & $\begin{array}{l}\text { Storage, sharing, and easy access to the data } \\
\text { remotely and on-demand based on the } \\
\text { competitive costs and according to the customer } \\
\text { requirements. }\end{array}$ & {$[22,23]$} \\
\hline Robotics (R) & $\begin{array}{l}\text { Applying automatic robots to complete tasks } \\
\text { automatically or in collaboration with humans to } \\
\text { provide more flexibility and safety in } \\
\text { workplaces. }\end{array}$ & {$[24]$} \\
\hline Sensor Technology (ST) & $\begin{array}{l}\text { Enabling checking, monitoring, and controlling } \\
\text { different internal and external activities related } \\
\text { to the products. Its capabilities are range from } \\
\text { sensing the quality status to the other } \\
\text { applications in the shop floor and life cycle } \\
\text { assessment. }\end{array}$ & {$[21,23]$} \\
\hline Omni Channel (OC) & $\begin{array}{l}\text { Making a seamless experience for the final } \\
\text { customer from shopping in different provided } \\
\text { both online and offline channels. }\end{array}$ & [25] \\
\hline Internet of Things (IoT) & $\begin{array}{l}\text { Making the link between objects and information } \\
\text { systems to collect real-time data about the } \\
\text { location and other features of the object by } \\
\text { connecting to the internet systems. }\end{array}$ & {$[22,26]$} \\
\hline Self-Driving Vehicles (SDV) & $\begin{array}{l}\text { SDVs are capable to find their way without } \\
\text { human intervention by self-navigation and } \\
\text { sensing. }\end{array}$ & {$[21]$} \\
\hline $\begin{array}{l}\text { Unmanned Aerial Vehicles } \\
\text { (UAV) }\end{array}$ & $\begin{array}{l}\text { A flying platform to use for different proposes } \\
\text { without the need to pilot and controllable based } \\
\text { on predetermined program or remote control. }\end{array}$ & {$[21,27]$} \\
\hline $\begin{array}{l}\text { 3D printing and Additive } \\
\text { Manufacturing (AM) }\end{array}$ & $\begin{array}{l}\text { Producing customized or urgent needs products } \\
\text { from 3D printing models by layer upon layer } \\
\text { procedure from using one source of materials. In } \\
\text { this procedure, there is no need for the assembly } \\
\text { of parts. }\end{array}$ & {$[22,23]$} \\
\hline Blockchain (BC) & $\begin{array}{l}\text { A secure and safe manner to share and access } \\
\text { tamper-proof real-time data among different } \\
\text { stakeholders. }\end{array}$ & {$[24]$} \\
\hline Big Data Analytics (BDA) & $\begin{array}{l}\text { Knowledge extraction by analyzing the huge } \\
\text { amount of structured, semi-structured, or } \\
\text { unstructured data to facilitate the } \\
\text { decision-making process based on the obtained } \\
\text { knowledge. }\end{array}$ & {$[21]$} \\
\hline Artificial Intelligence (AI) & $\begin{array}{l}\text { Advanced analytical tool for providing better } \\
\text { perception about future possible scenarios for } \\
\text { different activities and operations in SC. }\end{array}$ & {$[23,24]$} \\
\hline
\end{tabular}


Table 1. Cont.

\begin{tabular}{lll}
\hline \multicolumn{1}{c}{ Industry 4.0 Technology } & \multicolumn{1}{c}{ Definition } & Reference \\
\hline & $\begin{array}{l}\text { The interconnected system of machines and } \\
\text { humans in all aspects reports the actual state of } \\
\text { each component to the central cyber via different } \\
\text { ways such as sensors, IoT, etc. to analyze, make } \\
\text { the appropriate decision, and learn from the } \\
\text { problem. }\end{array}$ \\
\hline Simulation & $\begin{array}{l}\text { Simulating different processes and operations of } \\
\text { the SC for different proposes such as education, } \\
\text { design product or process, process improvement, } \\
\text { etc with different methods. }\end{array}$ \\
\hline
\end{tabular}

Recently, the growing attention to Lean and Industry 4.0 technologies as an emerging area [5] has led to an increasing number of literature contributions, especially in the form of SLRs. Table 2 indicates previous SLRs in this regard and compared them with contributions of the present work. Therefore, in this table, the investigated perspectives for each paper have been marked with $\left({ }^{*}\right)$. However, the number of such works is still limited [28-30]. Previous SLRs mainly investigate the relation between Lean and Industry 4.0 by focusing on the manufacturing process, without taking into account the other key SC processes, such as for example the logistics one [5,12,13,19,28,29,31-33]. Nevertheless, the impact of Lean DSC should be studied by addressing the complexity of SCs made of multiple processes and tiers [33,34]. Moreover, based on Table 2, the majority of the mentioned SLR papers study the connection between Lean principles and Industry 4.0 without investigating the effects of each digital technology individually. However, each of these technologies has specific characteristics and features that make it suitable to be applied in a Lean environment [35]. Therefore, this is important to figure out the relationships between Industry 4.0 technologies and Lean principles in Supply Chain Management (SCM) [19] by focusing on each of them. Additionally, SC members need to know the advantages and capabilities of each digital technology for addressing the SC at both operational and organizational levels [36], as well as the effects on decisions to cope with network complexity [37]. Furthermore, choosing appropriate technologies is a strategic task in Industry 4.0 [29], due to the fact that an improper selection can hinder Lean achievements rather than helping them. Therefore, due to the high investment cost associated with Industry 4.0 technologies, SC members need to identify the most applicable ones that are compatible with Lean contexts, so that to set implementation priorities [38].

Based on what was discussed above, the present SLR compared to the previous ones (Table 2), by investigating different perspectives, aims to provide a framework to illustrate the potential areas of application of each digital technology in relation to Lean principles to SCs. To the best of our knowledge, this is the first SLR about Lean DSC based on a comprehensive range of SC processes, operational (e.g., information sharing and activities scheduling) and organizational issues (e.g., risk and performance management). Additionally, the present study investigates all the main methodologies that were used by previous literature contributions to investigate Lean DSC as well as the integration between different digital technologies. 
Table 2. Summary of the previous works.

\begin{tabular}{|c|c|c|c|c|c|c|c|c|c|c|}
\hline$\frac{n}{0}$ & 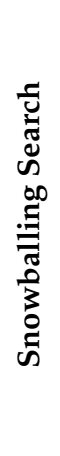 & 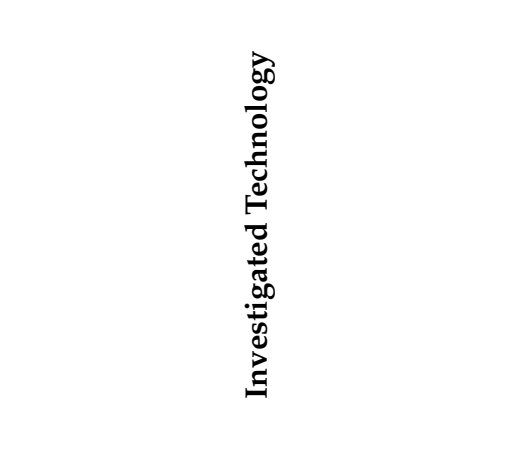 & 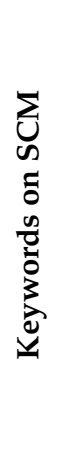 & 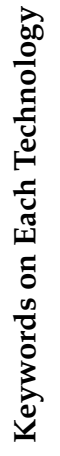 & 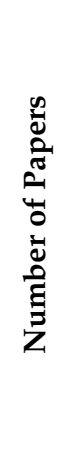 & 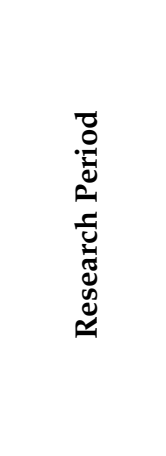 & 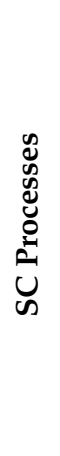 & 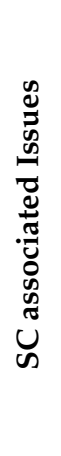 & 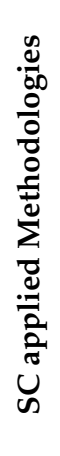 & 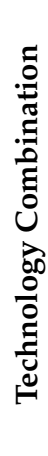 \\
\hline [29] & & & & & 31 & 2012-2016 & & & & \\
\hline [12] & & & & & 21 & 0-2017 & & & * & \\
\hline [5] & & & & & 26 & 2011-2018 & & & & \\
\hline [31] & & CPS, IoT, BDA, CC, VR, AR, R, 3DP & & & 54 & 2015-2018 & & & & \\
\hline [32] & & IoT, CPS, CC, BDA, R, AM, AR & & * & 93 & 0-2018 & & & * & \\
\hline [39] & * & CC, IoT, AI, VR, AV, BDA & * & * & 78 & 1996-2019 & & & * & \\
\hline [13] & & BDA, CPS, R, IoT, CC, AR & & $*$ & 115 & 0-2019 & & & & \\
\hline [19] & & & & & 47 & 2011-2018 & * & & & \\
\hline [33] & & & & & 22 & 2015-2019 & & & & \\
\hline [28] & & & & & 33 & 2011-2019 & & & & \\
\hline $\begin{array}{c}\text { Present } \\
\text { work }\end{array}$ & * & IoT, BDA, CC, BC, AM & * & * & 64 & $0-2020$ & * & * & * & * \\
\hline
\end{tabular}

* the investigated perspectives for each paper.

\section{Materials and Methods}

In the following sections, the approach for developing the present SLR will be described in detail.

\subsection{Planning the SLR Process}

The content analysis identified as SLR is a structured approach to give an overview of a specific subject by a step-wise and scientific procedure [40,41]. SLR is distinguished from the other approaches to study the state of the art, due to the reduction of the effects of subjective judgment [42] and the ability to provide deeper insights helping a discipline to move forward [43]. Present SLR follows the procedure proposed by [44], which unfolds in the following three steps: 1. planning the review process, 2 . searching and conducting the review, 3. reporting results and recommendations. Figure 1 depicts the steps for conducting SLR and the main activities of each step that will be explained in more detail in the next sections.
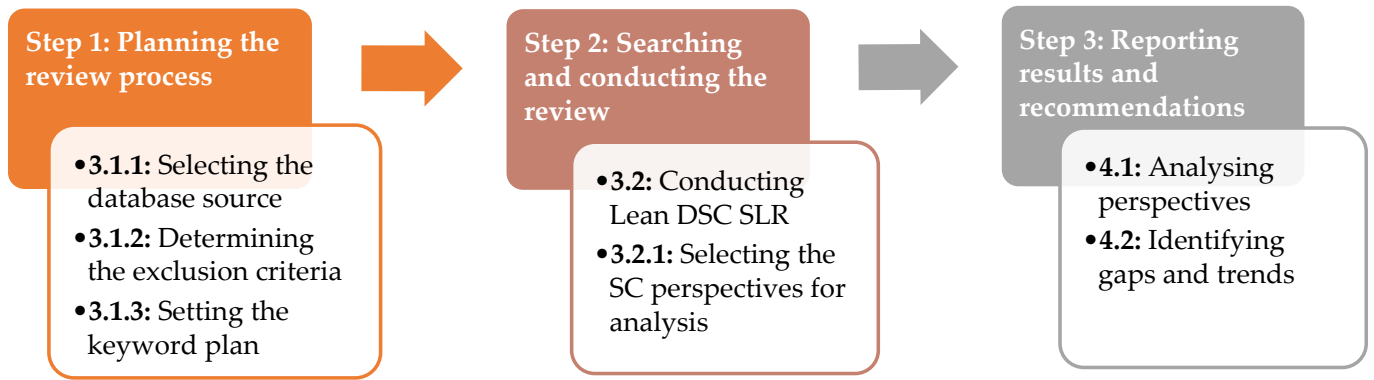

Figure 1. Adopted SLR procedure. 


\subsubsection{Selection of the Database Source}

One of the basic steps for conducting an SLR is selecting a reliable and comprehensive database source. In this regard, Scopus is recognized as the main searching source by many SLR papers in the field of SCM [45]. In fact, Scopus covers various disciplines [46] and a more comprehensive number of journals than other literature resources [47] since it includes the papers in databases such as Web of Science [42,45,48]. In this regard, the authors based on [12], which is the work performing a comparison among Scopus, ProQuest, Web of Science, Science-Direct, and EBSCO databases for searching in the field of SC in a combination of LEAN and Industry 4.0, aim to figure out which database is the most comprehensive one. Finally, this comparison revealed that Scopus is the most valuable database by retrieving most of the related papers. However, from ScienceDirect and EBSCO least number of related papers were obtained. Hence, for performing the present SLR Scopus is considered for searching the relevant keywords. Moreover, from the results of Table 2, it is obvious that the majority of the SLR papers in this field have not been conducting a snowballing search. However, the authors in the present work, to be sure about the completeness of the obtained results, performed both forward and backward snowballing as a complementary procedure. In this regard, scientific data sources other than Scopus, such as ProQuest, Web of Science, Science-Direct, and EBSCO databases were investigated especially in relation to backward snowballing.

\subsubsection{Determining the Exclusion Criteria}

Setting appropriate exclusion criteria leads to addressing the most relevant papers in the SLR process [49]. To this end, two levels of exclusion criteria were defined. At the first level, exclusion criteria are considered for filtering the search results obtained by Scopus. Therefore, the paper language is limited to English as the most prevalent one in scientific papers [50]. Moreover, Lean DSC is a newborn research field and has not yet matured enough, therefore, both conference and journal papers are included in the investigation. There is no limitation at this step on the other result fields such as subject area or publishing stage. Afterward, second-level exclusion criteria are defined to narrow the search results. Therefore, while investigating the title, abstract, and keywords from the previous step, or for studying full papers, the following criteria were considered: (a) Papers that do not refer to SCM; (b) Papers that are not related to Lean concepts; (c) Papers that do not mention considerable contributions about the application of Lean and digital technologies to SCM; (d) Papers that are more related to computer science; (e) Duplicated papers; (f) Papers that were published before 2010 with zero citations, due to the fact that the notion of Industry 4.0 and the trend of research on its main technologies were born after 2010. The comprehensive list of all the rejected papers and the associated reasons are available from the authors.

\subsubsection{Setting the Keyword Plan}

This research aims to figure out the relevance of using both digital technologies and Lean principles in SCM. Therefore, the literature search is conducted based on three levels of keywords. The selection of keywords for each level will be motivated in the next sub-sections.

\section{First-level keyword selection (Supply Chain)}

The keyword "supply chain" was first applied to delimit the search scope. It helps to obtain all the possible results about the context of this SLR.

Second-level keyword selection (Digital technologies)

Industry 4.0 as a general concept is characterized by many definitions and includes various digital technologies [22]. Hence, due to the vagueness of selecting the related keywords in the previous works $[10,12,13,39]$, the present SLR aims to provide a reliable basis for the literature searching by identifying the Industry 4.0 technologies most debated in SCM.

Selecting relevant keywords for emerging Industry 4.0 technologies in SCM. At the first step, the most relevant keywords are collected from [21,24,26,43,51-55]. Due to the 
early stage of the research about Industry 4.0 technologies in SCM [40,42,56], the first list of keywords is checked during the next phases of the research by the papers obtained from Scopus. However, the comparison confirmed the completeness of the first list of keywords. These fifteen keywords are Augmented Reality (AR), Cloud Computing, Robotics (R), Sensor Technology (ST), Omni Channel (OC), Internet of Things, Self-Driving Vehicles (SDV), Unmanned Aerial Vehicles (UAV), Nanotechnology (N), 3D printing and Additive Manufacturing, Blockchain, Big Data Analytics, Artificial Intelligence (AI), Cyber-Physical Systems (CPS), and Simulation. Only the keywords mentioned more than one time in the reference papers [21,24,26,43,51-55] are selected. Thus, the keywords "Sensors Technology", "Nanotechnology", and "Simulation" are identified as non-relevant keywords for searching about digital SCM. Afterward, the remaining keywords are checked with two SCM experts, and, by considering the scope of the research, "Omni channel" is removed from the list. Additionally, in order to minimize the possibility of missing relevant works in Scopus, all the possible variants of the keywords in the final list are searched, e.g., both "Block chain" and "Blockchain". The searching protocol is using a combination of each the selected keywords with Supply chain as the second level keyword (e.g., "Supply chain" AND "Cloud Computing") in the paper title, abstract, and keywords. Additionally, with the aim of addressing high-quality scientific contributions [57], the search focuses only on journal papers as the main resource for selecting technology keywords. The time for searching these queries is October 2020.

Refining the most relevant keywords for Industry 4.0 technologies in SCM. In this step, all the titles, abstracts, and keywords of the English journal papers from the results of the previous step are scrutinized. By doing this step, the main aim is refining the list of the Industry 4.0 technologies to remove the technologies that have no strong relationship with the SCM based on the published English journal papers. Based on the outcomes of reading title, keywords, and abstract, the total average percentage of relevant papers to the SCM $(34 \%)$ is considered as a criterion to identify the relevant digital technologies. Therefore, by removing the CPS and $\mathrm{R}$ the following technologies are considered as technologies to analyze in more detail in the next step: BC, BDA, AM, AR, IoT, SDV, AI, UAV, CC.

Identifying the most debated digital technologies in SCM to be used as keywords. As a further step of the analysis to finalize the list of the Industry 4.0 technologies in SCM, the trend of publications on each technology is here investigated. By doing this step, the main goal is completing the results of the previous step by taking look at the trend of publications for each single digital technology. It leads to focus on addressing the well-developed technologies in SCM. After analyzing the relevant papers based on their publication date, two groups of digital technologies are identified. The first one includes digital technologies that have recently acquired a growing interest, as witnessed by the increasing number of publications about SCM (Most debated technologies). The second group comprehends those digital technologies that either are debated in a decreasing number of publications in the last few years or do not have a steady increasing trend in the number of related SCM publications (Least debated technologies). Hence, based on the results from Figure 2, the most debated Industry 4.0 technologies in recent years are: BC, CC, BDA, AM, and IoT. Therefore, this group is considered as the main technology to search as the second level keywords. The group of least debated technologies in SCM (Figure 3) includes UAV, AR, SDV, and AI. Finally, to provide a comprehensive picture of contributions on digital technologies and Lean DSC, "Industry 4.0" and "digital" were added to the list of second level keywords. 


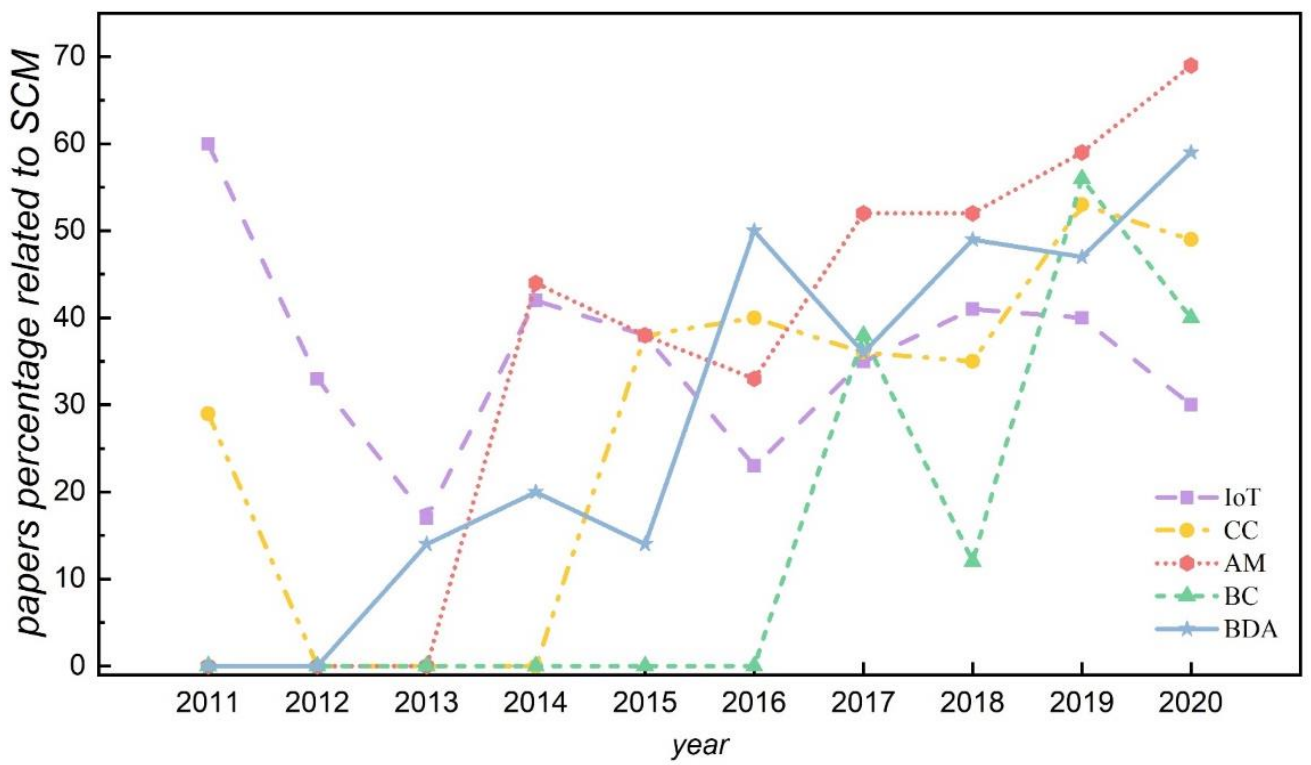

Figure 2. Most debated digital technologies in SC.

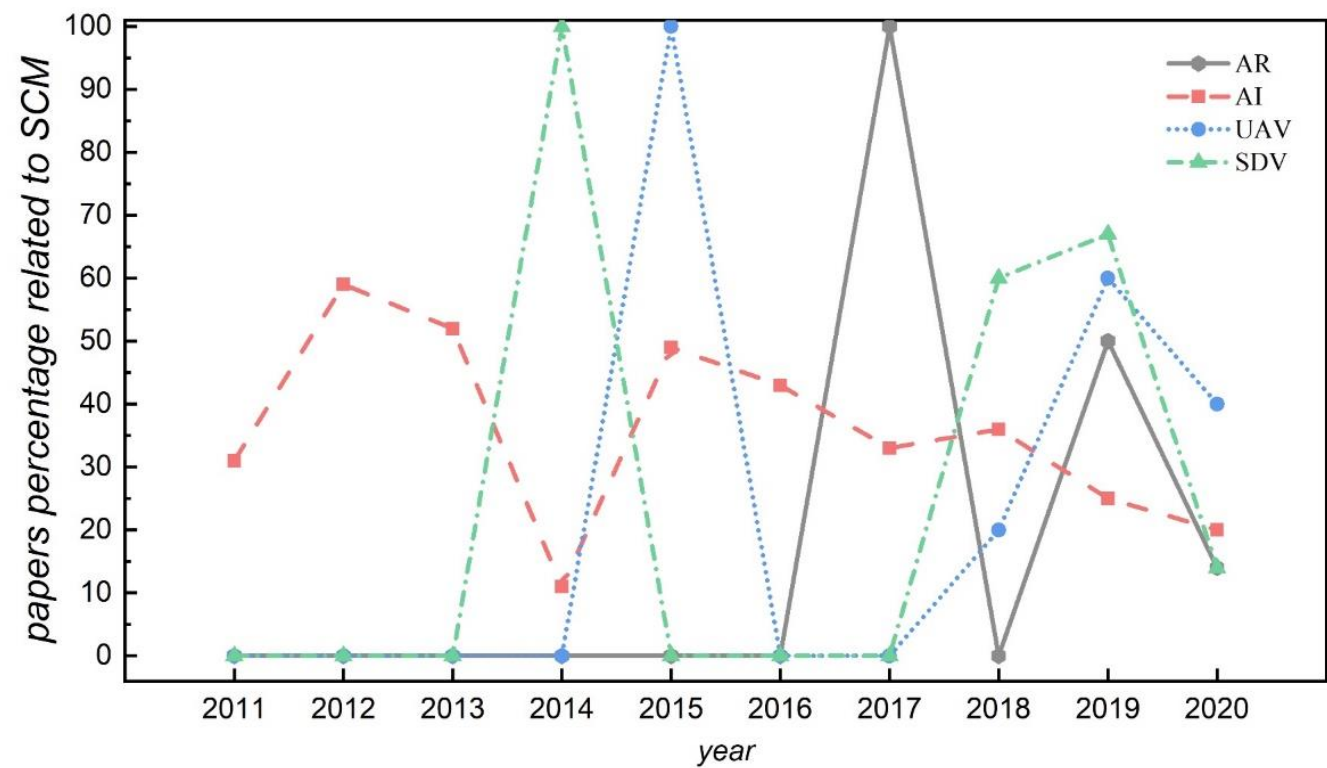

Figure 3. Least debated digital technologies in SC.

Third-level keyword selection (Lean principles)

The previous SLRs about the relationship between Lean principles and digital technologies mostly address that by making comparison among each specific Lean tool (e.g., $5 \mathrm{~s}$, Kanban, JIT, etc.) and single digital technologies at the production level [13,31]. However, the missing point is the impact of Lean principles and digital technologies at the SC level. To this end, the present work considers "Lean" as a general keyword in combination with the keywords about digital technologies and SC that were previously identified, in order to discover all the possible related works.

\subsection{Conducting the SLR on Lean DSC and Classification Framework}

After finalizing the review process plan, the results for conducting the SLR are described in this section and summarized in Figure 4. By combining the three keyword levels, 229 papers are found by searching in Scopus. Afterward, the results were limited to English journals and conference papers, obtaining 172 papers. Then, to address the main aim of the paper and obtain consistent results, the papers are removed based on the other 
mentioned exclusion criteria in Section 3.1 .2 by reading the title, abstract, and keywords. A total of 58 papers are kept in the dataset after this step. Moreover, in the process of reading full papers, authors continuously checked the relevance of the papers to the main aim of the research by referring to the same group of criteria in Section 3.1.2. Therefore, after investigating all papers, 25 papers were kept. In the next step, to be sure about the completeness of the database, forward and backward snowballing were conducted [58]. In backward snowballing, 33 additional papers are found by investigating the reference list of each previously qualified paper. Then, forward snowballing is carried out on the citation list of the 25 originally qualified papers based on Scopus, which added 6 further papers to the database. Totally, 64 papers are investigated to construct a comprehensive content analysis. Microsoft Excel ${ }^{\circledR}$ is used to build a data extraction form including the following fields: 1. Paper Information (paper title, year of publication, name of authors, name of journal, related information about journals such as impact factor and journal quality-Q1, Q2, etc., number of citations to the paper), 2. Searching Information (keywords for finding the paper in Scopus, link to the manuscript webpage), 3. Preliminary Paper Analysis (paper keywords, subject area, applied digital technologies, applied methodology, the source for data collection, research gap, research questions, main findings, limitations, future directions), 4. Detailed Paper Analysis (summary of the main points, critical analysis, relevance to the goal of the present research). In order to minimize the bias in the whole process of selecting and analyzing the papers, all the authors had regular weekly meetings to discuss and solve any doubts for each paper from October 2020 to June 2021.

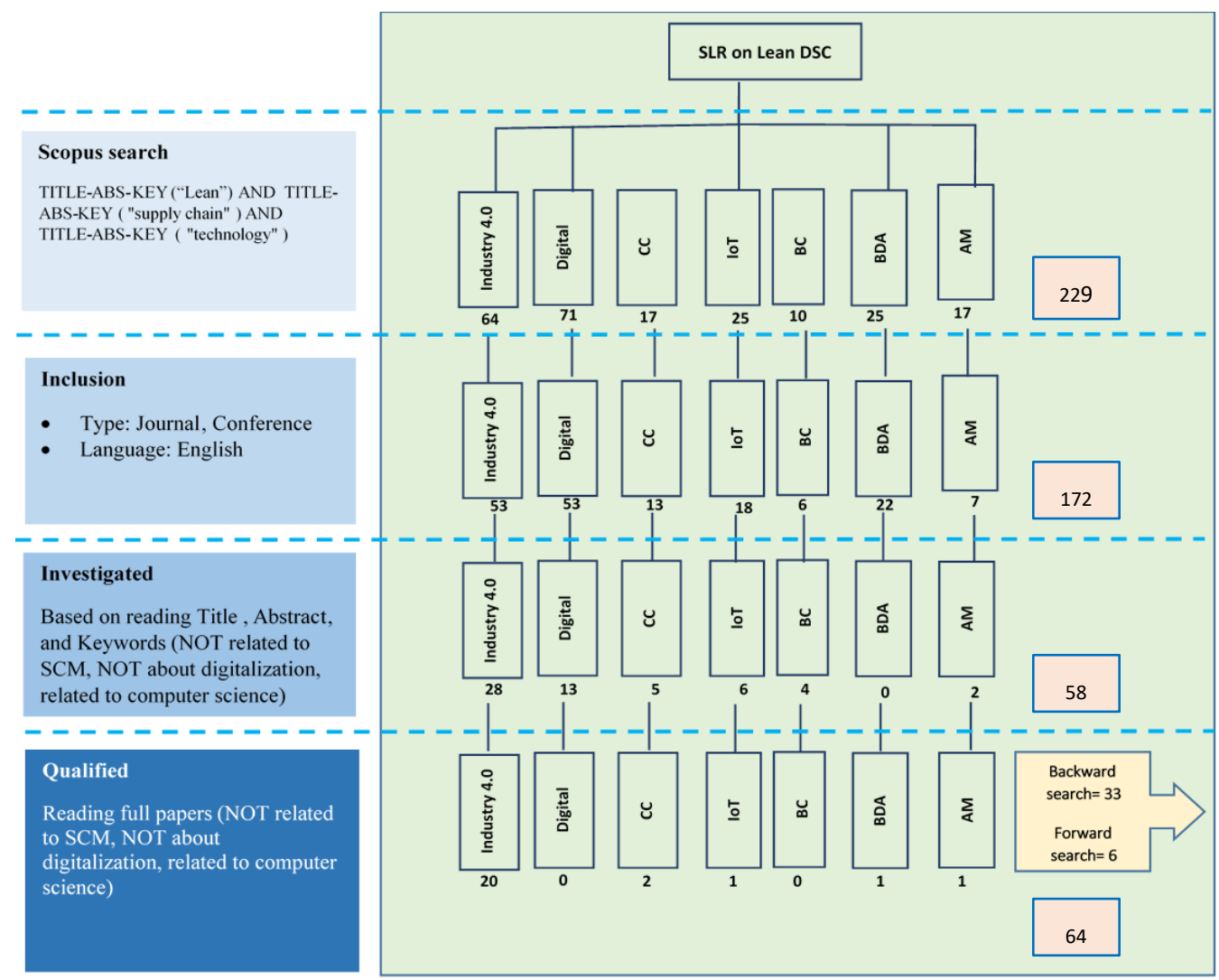

Figure 4. Results of SLR search.

Based on full paper reading and the data extraction form, a framework is proposed to classify the results, which is fruitful to pave the way for developing future research avenues in the next steps. The following subsections explain the structure of such a framework and the main motivations to consider each of its perspectives. 
Selecting the SC Perspectives for Analysis

The framework adopted to analyze the retrieved papers on Lean DSC includes the following perspectives. It is worth noting that the assignment of papers to each perspective is not mutually exclusive.

(a) Supply Chain Processes. The benefits brought by digital technologies to each individual SC process should be addressed [24] to illustrate their capability to enhance each single process and also identify the most related digital technologies. Moreover, Lean principles are mostly perceived by the existing literature as a tool for the improvement of the production process, and their adoption in the other SC processes is still scarce [19]. In this paper, the following list of SC processes was addressed based on the works by $[59,60]$ to make a comprehensive view of all SC activities: Procurement, Warehousing, Inventory Management, Manufacturing (Production), Transportation, Customer Relationship, Demand Forecasting, Marketing, and Pricing. It should be noted that by warehousing authors mean all the activities related to the organization of the warehousing process and products storage. However, in Inventory Management authors refer to the different activities for controlling and ordering the inventories and all related issues to inventory policy. Additionally, the Authors address the papers that they did not mention any specific process as focusing on the overall supply chain process.

(b) Supply chain-associated issues. The suggested framework pays special attention to the impact of each digital technology on the supply chain operational and organizational issues in relation to Lean principles. To this end, prevalent operational and organizational issues were considered as information sharing, revenue/cost-sharing, risk measurement/assessment, performance measurement/assessment, sustainability, financial, scheduling, business model. In fact, information sharing is deeply affected by Lean DSCs in the way of connecting echelons and in how they manage their value-added flows [61]. Moreover, real-time data provided by digital technologies can facilitate sustainability efforts in Lean DSCs [62]. For instance, real-time data provided by digital technologies such as blockchain can facilitate the over-processing of controlling and checking the sustainability indices. Similarly, they can lead to improving risk control in SCs [28]. Real-time data can also change the manner of scheduling SC tasks by making it more flexible to accommodate changing production needs. Furthermore, both practitioners and academicians are interested in discovering the effects on SC performance by Lean principles and digital technologies. Additionally, revenue cost/sharing is another important issue in this realm for two reasons: first, the effect of SC transparency leads to enhance the trust [63] and encourage SC members to adopt a revenue/cost-sharing policy in order to have a better collaboration for reducing inventory, over-processing, and over production as Lean wastes. Aside from that, SC members can consider revenue/cost sharing as an incentive to implement Lean DSC and increase its adoption rate.

(c) Supply chain applied methodologies. There is a lack of a roadmap to guide practitioners in implementing the Lean DSC [8]. To this end, investigating the methodologies applied by the previously published papers can assist academicians in figuring out appropriate approaches for assessing the existing theoretical contributions to construct a guideline for real implementation. As a result, based on previous works $[60,64,65]$, this SLR analyses the following methodologies: optimization/mathematical modeling, simulation, survey/case study, literature review, conceptual framework, hypothesis testing, model/architecture development, development of tool/platforms/computer system, Multi-Criteria Decision Making (MCDM) models.

(d) Combination of digital technologies in SCM. Integration has a significant impact on the efficiency and effectiveness of SCs [66]. However, applying individual digital technologies cannot achieve the goal of making a reliable infrastructure for full SC integration [63]. In this regard, prominent practitioners tend to aggregate a bunch of digital technologies to achieve enough mature solutions [23]. Additionally, due 
to the high investment cost of implementing digital technologies, it is valuable to identify their most beneficial combinations with the aim of promoting Lean efforts in SCM [67].

\section{Literature Review Outcomes}

The present section has two different subsections. Firstly, in Section 4.1 the outcomes out of the SLR were addressed from different perspectives in a more descriptive way. Secondly, in Section 4.2, a critical analysis was performed based on the results of SLR. In this part, the critical points of each perspective were identified in relation to its connection with Lean principles.

\subsection{Presentation of the Perspectives Outcomes}

In this section, the outcomes of the SLR are presented based on the investigated papers and summarized by graphical representations. Moreover, they are assigned to each analyzed perspective.

(a) Supply chain processes. Based on the results of the content analysis, Figure 5 shows that the majority of the previous papers study the effects of digital technologies on SCs as an overall process [68-70]. In fact, there are few papers that investigate the impacts of each individual technology on specific SC processes. However, IoT appears to be more investigated than the other technologies in relation to Lean principles application in different processes such as Warehousing, Manufacturing, and Inventory Management. Additionally, there are a few papers studying the BDA effects on Lean warehousing. On the contrary, there is no evidence about adopting AM and CC in single processes in Lean DSC, although, they were investigated to address the overall SC.

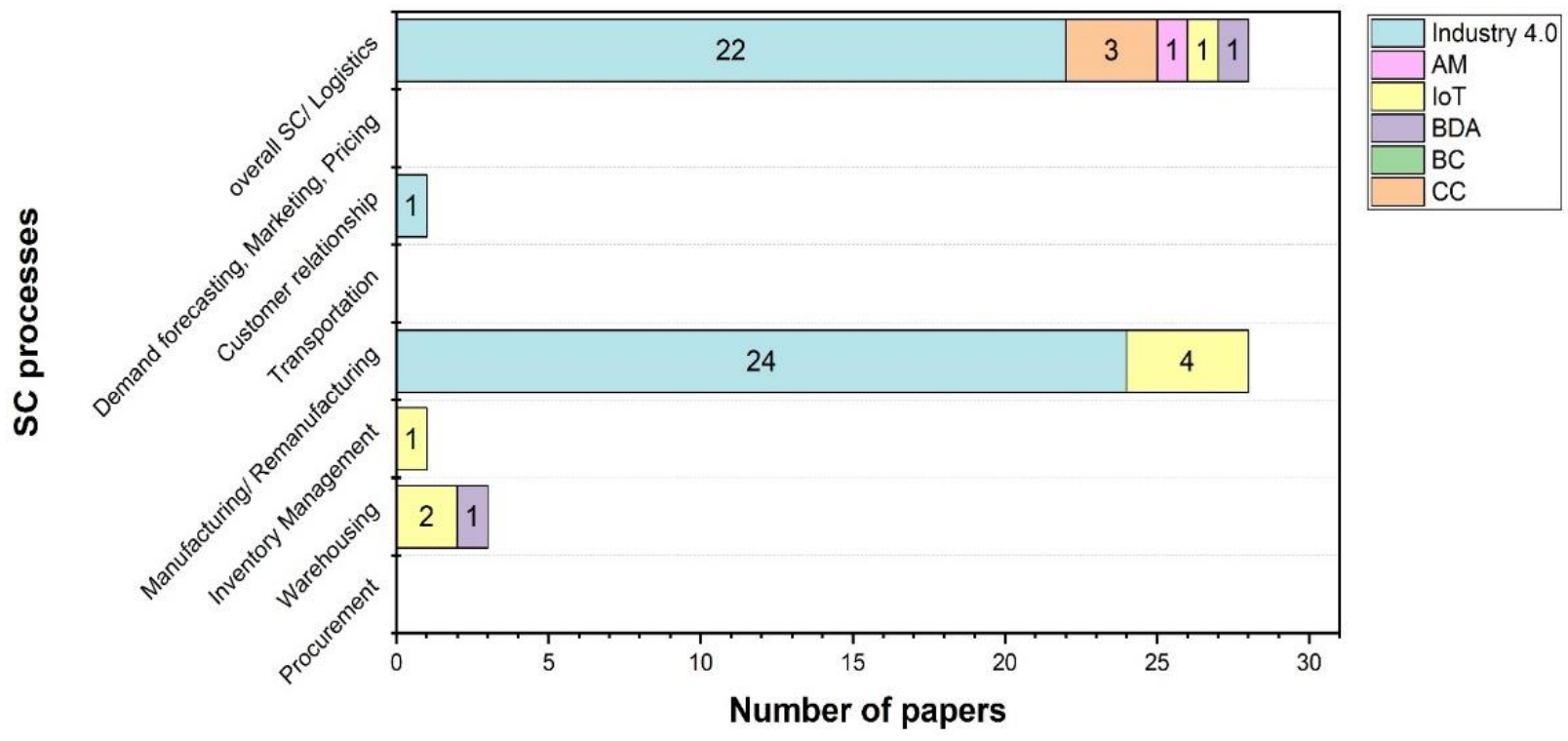

Figure 5. Distribution of papers: SC processes.

(b) Supply chain-associated issues. According to the results depicted in Figure 6, a considerable part of the investigated papers studies the impacts of Lean and digital technologies on information sharing as a key operational SC issue. However, a vast amount of papers still does not discover the effects of Lean DSC on the other SC issues in order to devise solutions to increase SC efficiency. For example, scheduling, risk management/assessment, and revenue/cost-sharing. Nevertheless, there are few efforts to improve sustainability by combining Lean principles and digital technologies. In this regard, CC, BDA, AM, and Industry 4.0 as a general concept 
are applied to enhance the main pillars of sustainability. However, for each single technology researchers just referenced the environmental effects and they did not address the impact of each single technology on the other three bottom lines such as economic and social issues. Moreover, a noticeable number of papers evaluate the effects of Lean DSC on performance assessment/measurement but the investigated digital technologies are limited to CC, BDA, IoT, and also these works mostly refer to Industry 4.0 in general.

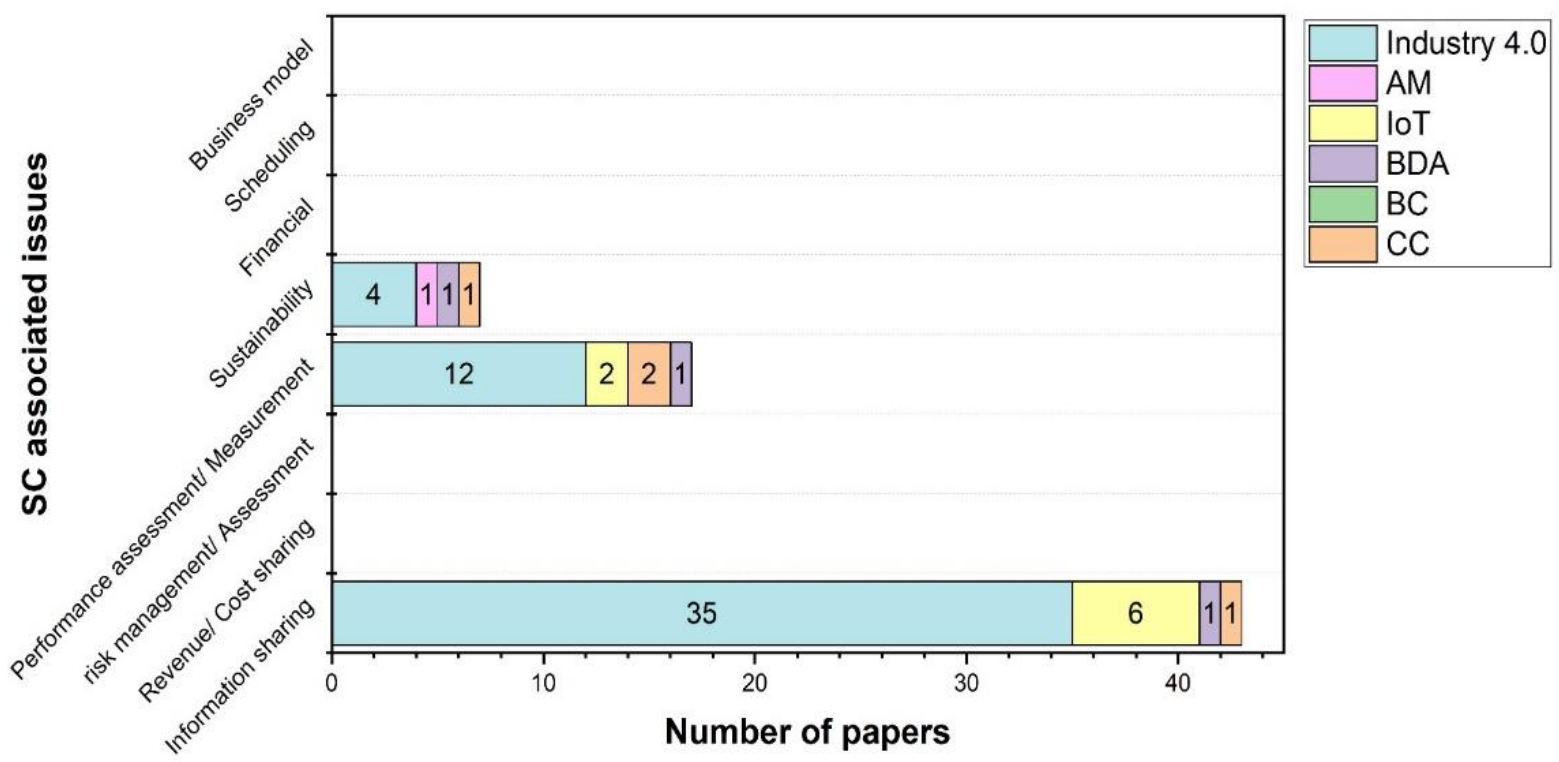

Figure 6. Distribution of papers: SC-associated issues.

(c) Supply chain-applied methodologies. Various methodologies are currently applied to address the Lean DSC (Figure 7). To this end, the survey/case study category reveals as the dominant one for investigating CC, BDA, IoT, and Industry 4.0 in general, applied together with Lean principles. Additionally, it should be noted that, except for the work by [71] on AM, there is no paper applying the literature reviews to discuss single digital technologies in relation to Lean Manufacturing. Besides, conceptual framework proves to be a popular methodology, applied for debating CC, IoT, and Industry 4.0 in general. Additionally, hypothesis testing is considerably used but not adopted to study all the single digital technologies except for CC, and BDA. Surprisingly, less attention is paid to the application of simulation to Lean DSC. Nonetheless, this is a promising methodology to illustrate the possible impacts of the application of Lean DSC in different conditions to assist practitioners in developing appropriate implementation roadmaps. 


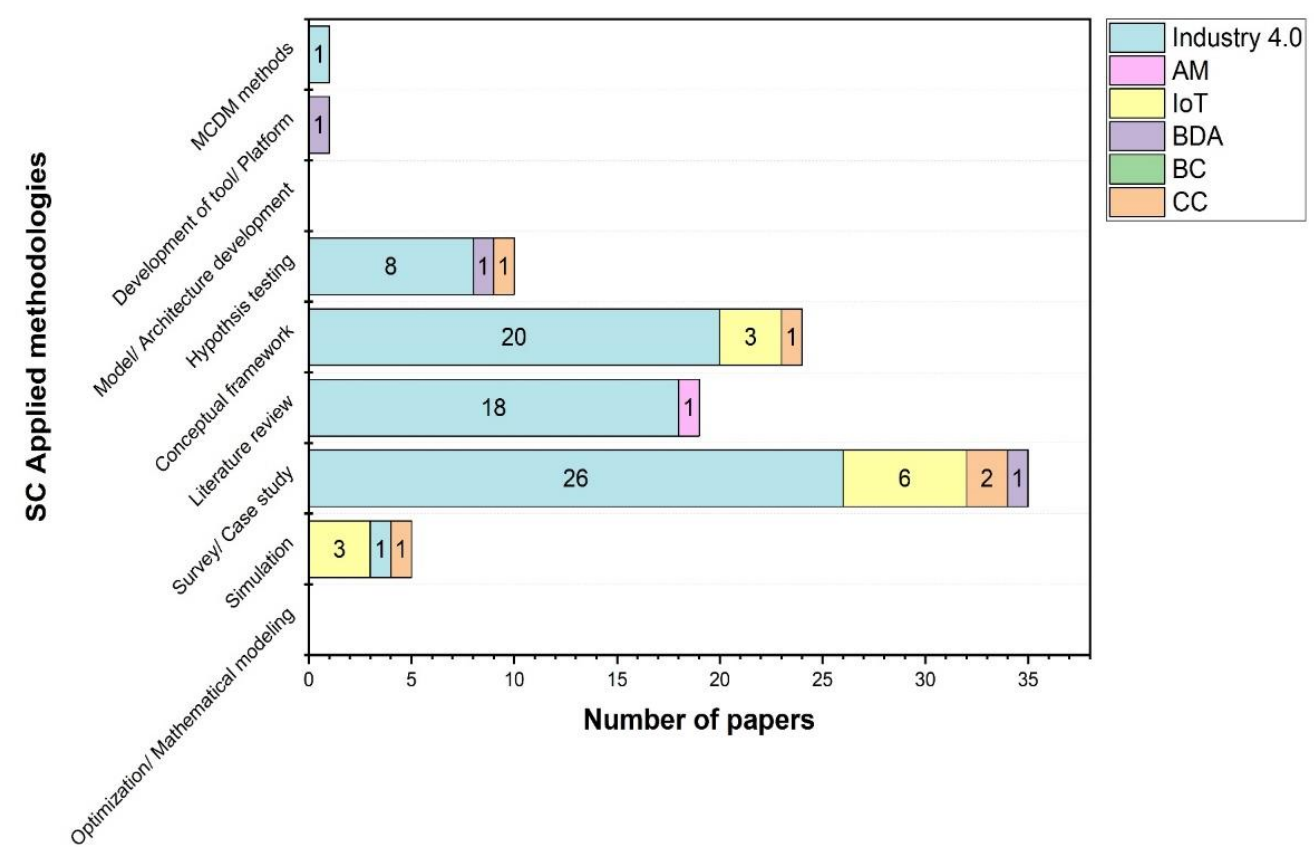

Figure 7. Distribution of papers: SC-applied methodologies.

(d) Combination of digital technologies in SCM. Figure 8 depicts a comprehensive picture of the combination of different digital technologies in Industry 4.0. All of the identified digital technologies at the end of step 1 in Section 3.1.3 are considered to figure out the power of each pair for concurrent application. The thickness of lines among each pair of digital technologies in Figure 8 indicates the strengthening of that relationship, calculated by dividing the number of papers considering the joint implementation of the two technologies by the total number of investigated works (64 papers). CC shows the most powerful relationships with BDA (22\%), IoT (20\%), and AM (19\%). AM is mostly applied associated with CC (19\%), BDA (17\%), and IoT $(16 \%)$. AR is mostly and equally mentioned with CC and BDA (16\% of the reviewed papers). Moreover, the evidence that emerged by reading papers reveals an interest of researchers in using BDA, CC, and IoT concurrently. On the other hand, based on Figure 8, BC needs to be investigated in the field of Lean DSC to figure out its potential applicability to improve SC.

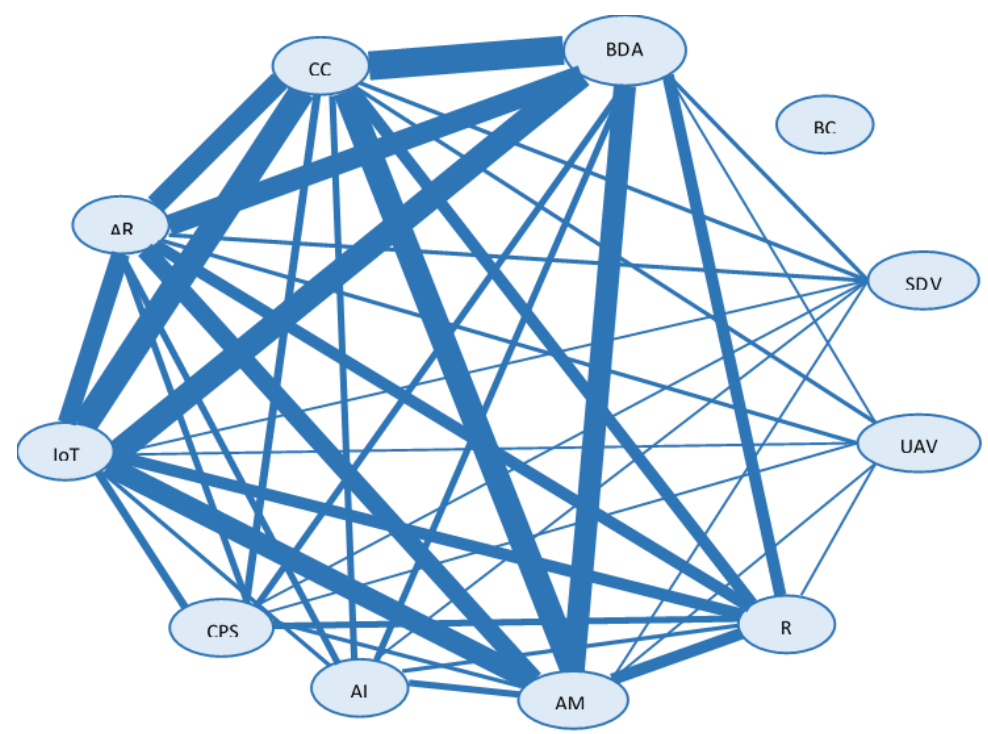

Figure 8. Assessing combinations of technologies in Lean DSC. 


\subsection{Interpretation of the Outcomes}

In this section, the outcomes of the SLR were critically analyzed to identify the gaps and trends in each perspective. To this end, Table 3 describes the main trends and gaps identified for each perspective adopted in the present SLR. As a general point about all of the investigated aspects, and based on the results discussed in Section 4.1, the great majority of papers investigate Lean DSC by considering Industry 4.0 as a general concept. This can arise from the novelty of Industry 4.0 as a newborn concept in SC. In this regard, the majority of previous works aimed to provide an overview of that to address its potentiality in Lean DSC. As a result, it could be convincing evidence to motivate the researcher for focusing on studying the Lean DSC from the perspective of each single digital technology of Industry 4.0 .

(a) Supply chain processes. These outcomes imply the necessity of studying the application of different technologies to eliminate waste from each SC process. By looking now at individual processes, the application of Lean and digital technologies is mostly discussed in manufacturing (Figure 5). Such an outcome stems from the fact that Lean principles were first introduced in production processes. However, the Lean philosophy can reduce non-value-adding activities in all the other SC processes. In fact, one of the main lacks of the present state of the art in Lean DSC is that no research is carried out on Procurement, Transportation, Demand Forecasting, Marketing, and Pricing processes. This lack could be stem from the fact that these issues are not directly connected to manufacturing as the main focus of the previous works in the realm of lean studies. As a result, this issue gives rise to finding fewer studies about the connection of mentioned issues and Lean DSC as a newborn field. However, for instance, SCs deal with marketing issues to forecast the demand specifically in short life cycle products and they should have better forecasting by removing non-valueadded activities to the customer. To this end, about the demand forecasting, BDA by analyzing SC data in different echelons, can provide a better understanding of customer needs that results in improvement of inventory waste [72]. BDA application can also provide a great opportunity to promote marketing policy and reduce the associated costs by identifying the most potential groups for advertisements as target customers [3]. As a result, it can enhance defining the marketing strategies and increase the efficiency of advertisement activities to attract the utmost customers regarding the time and cost of advertisements. To this end, the marketing group can dedicate its effort to defining the best strategy for each group of customers rather than identifying them. Therefore, that leads to reducing the over-processing waste in marketing activities. Furthermore, BDA helps to perceive the best time for considering discounts on perishable products with a limited shelf life to reduce inventory waste. To achieve that, practitioners might combine BDA with IoT to collect and analyze realtime data and CC to share information among different echelons. Additionally, BC by providing tamper-proof data can make a reliable and trustful database for applying BDA in forecasting the demand and marketing strategies for luxury goods or strategic items such as vaccines [73] during the COVID-19 pandemic. For instance, in the case of strategic items such as vaccines during the COVID-19 pandemic, governments can be sure about future decisions by more reliable demand forecasting to distribute the appropriate amounts of vaccines for different parts of the country. To this end, they can rely on the trustful data collected by BC and analysis provided by BDA. Moreover, about the luxury goods, BC can provide reliable information about the final customer data such as the location, final selling price, etc. Therefore, such reliable information can facilitate the precise analysis of BDA to assist the practitioners about potential points of real selling. Additionally, it can improve other issues related to the pricing of luxury goods to better control such issues and identify the cause of that by $\mathrm{BC}$ throughout the SC. These two examples, imply the improvement of doing these activities in terms of reducing over-processing as a Lean waste. 
Moreover, BDA and IoT can influence Lean efforts in reducing transportation and motion waste in warehouses by real-time analyzing the best product allocation policy. Again, in the warehousing process, the application of BC for specific cases, such as medicine and food, could reduce the time of auditing and inspection by providing data about the originality of materials or expiration dates. Therefore, by doing so $\mathrm{BC}$ can reduce waste such as over-processing and waiting. In addition, this can lead to fewer defects by providing instant and reliable data about the real state of the warehouse inventory such as expired products, amount of on-hand inventory, etc. In this regard, it should be combined with IoT for collecting the data, CC for sharing collected information, and BDA to analyze and propose the best decisions by considering different criteria in real-time. In this way, warehouses can have better inventory control and fewer defects. Additionally, for improving remanufacturing and closed-loop SC applying BC and IoT could be beneficial to collect reliable and instant data about the item's remaining life-cycle, expiration date, original producer to return, etc. This can reduce the efforts of over-processing of data and information to achieve a circular economy.

Furthermore, the development of BC applications in SC by providing tamper-proof data about suppliers' reliability can also lead to reducing over-processing in the procurement process by facilitating periodic supplier evaluation and providing a more reliable supplier selection process [74]. In this regard, all the suppliers from different echelons should be connected with BC systems that in turn could be integrated with the BDA system to analyze data and CC environment to share data from different supplies location. It can also result in having fewer defects as one of the Lean wastes, due to the fact that a more reliable and trustful procedure for supplier selection leads to improved quality of provided raw materials from the upstream suppliers and fewer defects in the production process.

(b) Supply chain-associated issues. As illustrated in Figure 6, the distribution of research papers on SC-associated issues is not homogenous. Thus, researchers should pay special attention to investigating the role of each single technology in improving the SC organization and operations. It seems that due to the novelty of Lean DSC, researchers are mainly focused on information sharing as one of the main aims of digital technologies. However, information sharing is not the focal point for all digital technologies. For instance, in the present literature, AM is just addressed in sustainability issues since by reducing transportation as a waste the amount of carbon emission is also reduced [75]. In this regard, the impact of AM on Lean DSC still should be discovered in the other related issues. For example, AM by reducing lead times can mitigate the risks that are related to disruptions in supply, transportation, and inventory. Therefore, AM can have a significant effect on improving the wastes of waiting, transportation, and inventory. Additionally, AM in combination with CC and $\mathrm{BC}$ can help to provide new business models by making novel experiences for the customer service. In fact, AM can promote the capability of product customization in a shorter time with cost-effective procedures. To this end, CC and BC can assist AM to access and share the customized product information in a real-time and reliable manner. Therefore, it leads to reducing the wastes related to waiting, transportation, and over-processing. Additionally, AM by linking to CC can also change the other components of business models such as supplier relations and key resources. In fact, real-time information sharing by $\mathrm{CC}$ and changing production procedures by $\mathrm{AM}$ can reduce the waste of inventory and overproduction. Moreover, adding AM machines in traditional production lines can affect scheduling issues. Indeed, AM machines can be useful for producing customized products, meeting unpredicted demand, reducing inventory backlogs, alleviating production interruption due to maintenance. Therefore, this can lead to reducing the waste of motion and waiting in Lean DSC. Moreover, constructing a system based on concurrently applying $\mathrm{BDA}$, IoT, and CC can make SCs more transparent. In fact, sharing the information 
about inventory level, customer demand, upstream and downstream suppliers, and transportation in a real-time manner can lead to better controlling risks and planning proactive actions for any potential disruptions [76]. In fact, this results in reducing overproduction, inventory, and waiting. As another suggestion, the advent of digital technologies such as BC can be useful for reducing the waste of over-processing in financial transactions by providing trustful data and making the payments easier and reliable [77]. Furthermore, applying BC can promote the efforts and willingness of SC members in constructing the revenue/cost-sharing contracts by enhancing the trust among different SC members. In fact, by doing so with blockchain SC members do not need to make decisions and control various parameters for constructing and keeping the revenue/cost-sharing contracts. In fact, defining and running the smart contract on $\mathrm{BC}$ can lead to reducing the over-processing in decision-making for practitioners in such contracts. As mentioned before by facilitating the adoption of such contracts in SC with applying BC leads to determining the prices with less dispute among SC members. Therefore, SC members can construct better coordination and collaboration in revenue/cost-sharing contracts throughout the SC to increase their market share [78]. The latest issue can improve the over-processing activities related to price determination.

(c) Supply chain applied methodologies. The high number of research relying on surveys and case studies reflects the scarce maturity of Lean DSC as an emerging field. In fact, currently, researchers explore the relationships between Lean principles and digital technologies by carrying out experimental studies. In this regard, hypothesis testing can be referenced as one of the potential methodologies to complete analysis by surveys and case studies. As a matter of fact, the researcher can develop innovative ideas related to possible effects and applications of Lean DSC and evaluate them in a scientific way by doing hypothesis testing. Additionally, many papers put forward conceptual frameworks, which can help to develop the main ideas of Lean DSC and its application. In fact, their main aim is to provide the baseline for motivating practitioners for real implementation of the Lean DSC concept in a scientific way. Based on Figure 7, optimization models and architecture development are not represented by the available literature. This could stem from the large quantity of data, also about the structure of a Lean DSC, required for developing these methodologies, which can be available only from real implementations of Industry 4.0 technologies. To this end, simulation models can help both academicians and practitioners to evaluate different scenarios about the implementation of Lean DSC before investing in them in the real world. Furthermore, based on the results of Figure 7, there is still room for doing research by SLR to investigate published contributions about individual digital technologies in Lean DSC. In fact, this methodology is valuable since it provides the last state of the art in the field which is beneficial for both practitioners and academicians to adapt their SCs based on the recent knowledge. Moreover, applying MCDM models can assist researchers to realize the most important factors to adopt Lean DSC in various industry sizes. In this regard, MCDM models can also represent the most important criteria for practitioners to help them evaluate their situation and level of readiness to apply Lean DSC in their SC.

(d) Combination of digital technologies in SCM. As discussed in Section 4.1, BDA, IoT, $\overline{\mathrm{CC}}$, are the digital technologies more frequently applied with other ones. In fact, their concurrent implication, by providing real-time data, makes the basic infrastructure for information sharing and decision making in different echelons. This is also compliant with the results obtained by $[50,79]$. For instance, just combining these three technologies at the first step of constructing DSC is according to lean principles by reducing the efforts to over-processing in different stages. In this regard, IoT can apply for collecting real-time data with less effort and CC can apply to integrate all the information instantly. Additionally, BDA by extracting the knowledge from different types of data can facilitate the process of decision making and decision analysis. Then, 
researchers and practitioners can gradually include the other complementary digital technologies that are relevant to their SC processes. Based on Figure 8, it can be stated that to achieve Lean goals, AM needs to be connected with the information-sharing system. In particular, it has a great connection with BDA, CC, and IoT. Moreover, by looking at the technologies that are least frequently combined together, for instance, $\mathrm{BC}$ can improve the trust among different SC members, so it might make them more willing to share information by CC. Moreover, improving trust to share information among SC members can also reduce the need for the auditing processes [62]. Therefore, this results in removing the over-processing waste. In addition, from the practical point of view, the combination of AM and BC can be fruitful since it can solve the current difficulties in AM adoption related to the licenses and copyright rules. In fact, BC can guarantee the originality of the 3D printing and AM models for the designer. Moreover, CC can combine with SDV to timely report any problem about their performance. Therefore, this leads to a decrease in waiting. Additionally, AR can be integrated with CC to assist SDV maintenance and decrease the required time and effort. Therefore, the mentioned technologies lead to improving the motion and waiting wastes. As another example, for specific applications such as light products or medical products, adding UAVs can improve last-mile delivery in Lean DSC by reducing transportation and waiting. To this end, UAVs should be supported by $\mathrm{CC}, \mathrm{BC}$, and IoT to collect and share reliable real-time information about product delivery. In addition, using UAVs can be beneficial in the warehousing process to improve inventory visibility and avoid over-processing and motion. In this regard, CC can assist in sharing the collected data by UAVs to integrate them with the other SC information systems and make a comprehensive analysis, also by using BDA.

Table 3. Main identified trends and gaps.

\begin{tabular}{|c|c|c|}
\hline Perspectives & Trends & Gaps \\
\hline 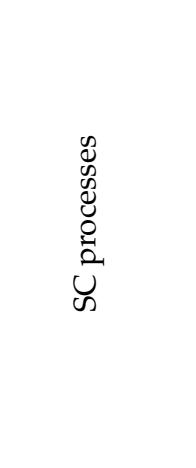 & $\begin{array}{l}\text { - Manufacturing is the most } \\
\text { analyzed process, both when } \\
\text { Industry } 4.0 \text { as a general } \\
\text { concept is addressed and } \\
\text { when single digital } \\
\text { technologies are debated. } \\
\text { IoT and Lean principles are } \\
\text { studied in a wider range of SC } \\
\text { processes than the other } \\
\text { digital technologies. }\end{array}$ & $\begin{array}{l}\text { - Few papers consider the effects of } \\
\text { Lean and each Industry } 4.0 \\
\text { technology on different SC processes, } \\
\text { in particular Inventory Management } \\
\text { and Customer Relationship. } \\
\text { - None of the previous research study } \\
\text { the Lean DSC applied to Procurement, } \\
\text { Transportation, Demand Forecasting, } \\
\text { Marketing, and Pricing. } \\
\text { No paper studies BC, AM and CC in } \\
\text { combination with Lean principles in } \\
\text { single processes. }\end{array}$ \\
\hline 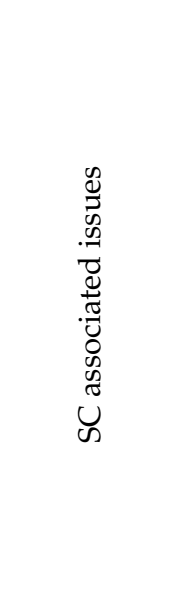 & $\begin{array}{l}\text { - Mainly papers focused on the } \\
\text { influence of digital } \\
\text { technologies on information } \\
\text { sharing as one of the major } \\
\text { aims of Lean DSC. } \\
\text { IoT is the most frequently } \\
\text { considered individual } \\
\text { technology to be studied } \\
\text { together with Lean principles } \\
\text { in SC issues. } \\
\text { Sustainability and } \\
\text { performance } \\
\text { assessment/measurement are } \\
\text { among the emerging issues to } \\
\text { be addressed in Lean DSC. }\end{array}$ & $\begin{array}{l}\text { - Limited number of studies about the } \\
\text { impacts of each single Industry } 4.0 \\
\text { technology on SC operational and } \\
\text { organizational issues. } \\
\text { Scarce investigation of the relevant } \\
\text { advantages of applying Lean and } \\
\text { digital solutions to SC } \\
\text { revenue/cost-sharing, risk } \\
\text { management/assessment, scheduling, } \\
\text { business modeling, and finance. } \\
\text { No work addressing the relationship } \\
\text { between IoT and sustainability issues } \\
\text { in the realm of Lean SC. } \\
\text { AM is just discussed in relation to } \\
\text { sustainability and needs to be further } \\
\text { developed in other SC issues. }\end{array}$ \\
\hline
\end{tabular}


Table 3. Cont.

\begin{tabular}{|c|c|c|}
\hline Perspectives & Trends & Gaps \\
\hline 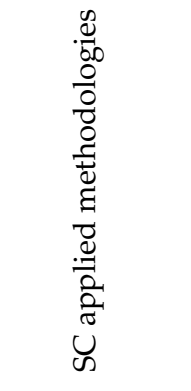 & $\begin{array}{l}\text { - Surveys and case studies are } \\
\text { the most applied } \\
\text { methodologies to Lean DSC. } \\
\text { Most of the works applying } \\
\text { the literature review approach } \\
\text { address Industry } 4.0 \text { as a } \\
\text { general concept. } \\
\text { IoT is the most prevalent } \\
\text { digital technology studied by } \\
\text { simulation approach. }\end{array}$ & $\begin{array}{l}\text { - No paper applying optimization and } \\
\text { architecture development to Lean } \\
\text { DSC. } \\
\text { Literature reviews rarely analyze } \\
\text { single digital technologies and no } \\
\text { works focus on CC, IoT, BDA, BC. } \\
\text { There is few applications of MCDM } \\
\text { methods, as well as digital platforms } \\
\text { for Lean DSC management. }\end{array}$ \\
\hline 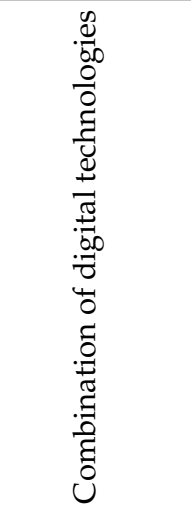 & $\begin{array}{l}\text { - IoT, BDA, CC, and AM are } \\
\text { frequently applied together to } \\
\text { SCs. } \\
\text { - CC is the digital technology } \\
\text { most often combined with the } \\
\text { other ones. }\end{array}$ & $\begin{array}{l}\text { BC needs to be combined with the } \\
\text { other DSC technologies } \\
\text { SDV, UAV, R, and AI have poor } \\
\text { connections with the other digital } \\
\text { technologies in the SCM field. }\end{array}$ \\
\hline
\end{tabular}

\section{Implications}

In this section, the most important implications for both academicians and practitioners were addressed based on adopted perspectives in the structure of the SLR framework. Therefore, the present SRL framework can help academicians in the following ways:

1. It provides a comprehensive analysis of the gaps in Lean DSC to better understand the possible future research directions on this newborn topic.

2. This work reveals the most prevalent methodologies to inspire the future study each Industry 4.0 technology in Lean DSC environments. The present SLR suggests the methodologies that might be applied by researchers in the next maturity stages of the Lean DSC.

3. Addressing the current state of the art about the application of Lean DSC on main operational and organizational issues can persuade researchers to focus on solving less debated issues by addressing the new advantages provided by the integration of Lean and Industry 4.0 technologies.

Moreover, from the practitioner's viewpoint, the following implications can be achieved:

1. By providing a comprehensive view of the main SC processes, it could be a starting point for practitioners to identify the best Industry 4.0 technologies to achieve Lean goals in each process. In this regard, the present SLR helps to identify the most applicable technologies in line with Lean principles to promote individual processes.

2. It helps to clarify the capability of each Industry 4.0 technology to provide solutions to main SC operational and organizational issues. Therefore, addressing the most valuable Industry 4.0 technologies in combination with lean principles can ignite the idea of how practitioners can apply them to the daily challenges in the SCM.

3. The concurrent application of different technologies was investigated. In this way, based on the SC situation, practitioners can determine which bunch of technologies are the most profitable ones to invest in them in order to guarantee successful outcomes. 


\section{Conclusions}

The quick development of the Industry 4.0 notion reveals the necessity of investigating the effects of the associated technologies on SCs. Moreover, to retain the market share, eliminating the non-value added activities by Lean principles could lead to a great competitive advantage [80]. Therefore, the present study focus on the opportunities created by using both Lean and Industry 4.0 technologies in SC. To this end, [19] mentioned that the application of Lean is mostly addressed from the side of single SC echelons because it is in conflict with the concept of Lean at the SC level. However, the results of the present work, by doing a comprehensive SLR, indicate the power of Industry 4.0 in combination with Lean principles to achieve a Leaner SC. In particular, SC members can improve trust and information sharing by using Industry 4.0 technologies such as BDA, IoT, CC, BC which leads to reducing over-production, over-processing, and inventory waste in multiple SC echelons. Additionally, revolutionizing the information sharing structure in SCs can facilitate the use of other Industry 4.0 technologies to pave the way for implementing the Lean approach in all the processes. For instance, data sharing and data protection provided by BDA, CC, IoT, and BC can increase trust and transparency. It leads to accelerating the AM adoption in different SC parts by providing a secure way to protect the license of innovative ideas to produce by AM. As a matter of fact, AM by reducing lead times can help to eliminate unnecessary motion, transportation, waiting, as well as to reduce defects. Therefore, the present work illustrates the capability of the combination of Industry 4.0 technologies and Lean principles to enhance SC structure by studying that from different perspectives.

There are some limitations in the present research. Despite the concerted efforts to follow a scientific procedure for setting the keywords for searching in scientific databases, there is a possibility of missing some relevant works. Furthermore, in the present contribution, the authors searched the keywords only in Scopus. Therefore, to alleviate these limitations, the present SLR completed with snowballing to be sure about covering all the relevant works. Additionally, in proposing the results and gaps it does not consider the impact of industry size on real practice adoption.

Although Section 4.2 and Table 3 already show some research directions about the investigated topic out of the SLR, the following suggestions for future works can be added. In this regard, with more development of Industry 4.0 in different aspects of SC, it could be valuable to assess the other Industry 4.0 technologies excluded from the present work to enhance the results of the SLR. Moreover, searching in other databases might lead to finding some newly published works in this field. Additionally, it could be beneficial to classify the results of the performed literature review based on their applicability from the perspective of different industry sizes. In fact, different industry sizes do not have the same resources to invest in constructing Lean DSC. Therefore, future research should address this issue by defining the most appropriate roadmap for each industry size. Moreover, depending on the industry size, relevant SCs can have different requirements. This should be considered by addressing the most appropriate solutions based on Lean DSC.

Author Contributions: Conceptualization, M.M.; methodology, M.M. and A.C.C.; formal analysis, M.M.; investigation, A.C.C. and C.R.; writing-original draft preparation, M.M.; writing-review and editing, A.C.C.; visualization, M.M.; supervision, C.R., A.C.C. All authors have read and agreed to the published version of the manuscript.

Funding: This research received no external funding.

Institutional Review Board Statement: Not applicable.

Informed Consent Statement: Not applicable.

Data Availability Statement: The data that support the findings of this study are available from the corresponding author.

Conflicts of Interest: No potential conflict of interest was reported by the author(s). 


\section{References}

1. Reschke, J.; Gallego-García, S. A Novel Methodology for Assessing and Modeling Manufacturing Processes. Appl. Sci. 2021, 11, 10117. [CrossRef]

2. Tan, B.Q.; Wang, F.; Liu, J.; Kang, K.; Costa, F. A blockchain-based framework for green logistics in supply chains. Sustainability 2020, 12, 4656. [CrossRef]

3. Ma, D.; Hu, J. Research on collaborative management strategies of closed-loop supply chain under the influence of big-data marketing and reference price effect. Sustainability 2020, 12, 1685. [CrossRef]

4. Alnahhal, M.; Ahrens, D.; Salah, B.; Khaimah, A. Dynamic Lead-Time Forecasting Using Machine Learning in a Make-to-Order Supply Chain. Appl. Sci. 2021, 11, 10105. [CrossRef]

5. $\quad$ Bittencourt, V.; Saldanha, F.; Alves, A.C.; Leão, C.P. Contributions of lean thinking principles to foster industry 4.0 and sustainable development goals. In Lean Engineering for Global Development; Springer: Cham, Switzerland, 2019; pp. 129-159. [CrossRef]

6. Ohno, T. The Toyota Production System: Beyond Large-Scale Production; Toyota Production System; Productivity Press; United States. 1988. Available online: https://www.taylorfrancis.com/books/mono/10.4324/9780429273018/toyota-productionsystem-taiichi-ohno-norman-bodek (accessed on 23 June 2021).

7. Douglas, J.A.; Antony, J.; Douglas, A. Waste identification and elimination in HEIs: The role of Lean thinking. Int. J. Qual. Reliab. Manag. 2015, 32, 970-981. [CrossRef]

8. Tissir, S.; Fezazi, S.E.; Cherrafi, A. Industry 4.0 impact on Lean Manufacturing: Literature Review. In Proceedings of the 2020 13th International Colloquium of Logistics and Supply Chain Management (LOGISTIQUA), Fez, Morocco, 2-4 December 2020.

9. Brinch, M. Understanding the Value of Big Data in Supply Chain Management and Its Business Processes: Towards a Conceptual Framework; International Journal of Operations and Production Management; Emerald Group Holdings Ltd.: Bingley, UK, 2018; Volume 38, pp. 1589-1614.

10. Lai, N.Y.G.; Wong, K.H.; Halim, D.; Lu, J.; Hooi, S.K. Industry 4.0 Enhanced Lean Manufacturing. In Proceedings of the 2019 8th International Conference on Industrial Technology and Management (ICITM), Cambridge, UK, 2-4 March 2019 ; pp. $206-211$.

11. Mayr, A.; Weigelt, M.; Kühl, A.; Grimm, S.; Erll, A.; Potzel, M.; Franke, J. Lean 4.0-A conceptual conjunction of lean management and Industry 4.0. Procedia CIRP 2018, 72, 622-628. [CrossRef]

12. Buer, S.-V.; Strandhagen, J.O.; Chan, F.T.S. The link between industry 4.0 and lean manufacturing: Mapping current research and establishing a research agenda. Int. J. Prod. Res. 2018, 56, 2924-2940. [CrossRef]

13. Rosin, F.; Forget, P.; Lamouri, S.; Pellerin, R. Impacts of Industry 4.0 technologies on Lean principles. Int. J. Prod. Res. 2020, 58, 1644-1661. Available online: https:/ / www.tandfonline.com/action/journalInformation?journalCode=tprs20 (accessed on 8 September 2021). [CrossRef]

14. Končar, J.; Grubor, A.; Marić, R.; Vučenović, S.; Vukmirović, G. Setbacks to IoT implementation in the function of FMCG supply chain sustainability during COVID-19 pandemic. Sustainability 2020, 12, 7391. [CrossRef]

15. Manavalan, E.; Jayakrishna, K. A review of Internet of Things (IoT) embedded sustainable supply chain for industry 4.0 requirements. Comput. Ind. Eng. 2018, 127, 925-953. [CrossRef]

16. Sahin, M.; Ko, H.S.; Lee, H.F.; Azambuja, M. A simulation case study on supply chain management of a construction firm adopting cloud computing and RFID. Int. J. Ind. Syst. Eng. 2017, 27, 233-254. [CrossRef]

17. Chiarini, A.; Belvedere, V.; Grando, A. Industry 4.0 strategies and technological developments. An exploratory research from Italian manufacturing companies. Prod. Plan. Control. 2020, 31, 1385-1398. [CrossRef]

18. Tortorella, G.L.; Miorando, R.F.; Fries, C.E.; Vergara, A.M.C. On the relationship between Lean Supply Chain Management and performance improvement by adopting Industry 4.0 technologies. In Proceedings of the International Conference on Industrial Engineering and Operations Management, Paris, France, 26-27 July 2018; pp. 2475-2484.

19. Müller, J.M.; Birkel, H.S. Contributions of Industry 4.0 to lean management within the supply chain operations reference model. Int. J. Integr. Supply Manag. 2020, 13, 74-89. [CrossRef]

20. Novais, L.; Marín, J.M.M.; Moyano-Fuentes, J. Lean Production implementation, Cloud-Supported Logistics and Supply Chain Integration: Interrelationships and effects on business performance. Int. J. Logist. Manag. 2020, 31, 629-663. [CrossRef]

21. Büyüközkan, G.; Göçer, F. Digital Supply Chain: Literature review and a proposed framework for future research. Comput. Ind. 2018, 97, 157-177. [CrossRef]

22. Raji, I.O.; Shevtshenko, E.; Rossi, T.; Strozzi, F. Industry 4.0 technologies as enablers of lean and agile supply chain strategies: An exploratory investigation. Int. J. Logist. Manag. 2021, 32, 1150-1189. [CrossRef]

23. Frank, A.G.; Dalenogare, L.S.; Ayala, N.F. Industry 4.0 technologies: Implementation patterns in manufacturing companies. Int. J. Prod. Econ. 2019, 210, 15-26. [CrossRef]

24. Moufaddal, M.; Benghabrit, A.; Bouhaddou, I. Industry 4.0: A roadmap to digital Supply Chains. In Proceedings of the International Conference on Smart Systems and Data Science (ICSSD), Fez, Morocco, 3-4 October 2019.

25. Chen, Y.; Cheung, C.M.K.; Tan, C.-W. Omnichannel business research: Opportunities and challenges. Decis. Support. Syst. 2018, 109, 1-4. [CrossRef]

26. Dalmarco, G.; Barros, A.C. Adoption of industry 4.0 technologies in supply chains. In Contributions to Management Science; Springer: Cham, Switzerland, 2018; pp. 303-319. 
27. Vergouw, B.; Nagel, H.; Bondt, G.; Custers, B. Drone Technology: Types, Payloads, Applications, Frequency Spectrum Issues and Future Developments. Inf. Technol. Law Ser. 2016, 27, 21-45. Available online: https://link.springer.com/chapter/10.1007/978-94 -6265-132-6_2 (accessed on 17 December 2021).

28. Bittencourt, V.L.; Alves, A.; Leão, C.P. Industry 4.0 triggered by Lean Thinking: Insights from a systematic literature review. Int. J. Prod. Res. 2021, 59, 1496-1510. [CrossRef]

29. Leyh, C.; Martin, S.; Schäffer, T. Analyzing industry 4.0 models with focus on lean production aspects. In Lecture Notes in Business Information Processing; Springer: Cham, Switzerland, 2018; pp. 114-130. Available online: https://link.springer.com/chapter/10.1 007/978-3-319-77721-4_7 (accessed on 28 June 2021).

30. Tortorella, G.L.; Fettermann, D. Implementation of Industry 4.0 and lean production in Brazilian manufacturing companies. Int. J. Prod. Res. 2018, 56, 2975-2987. [CrossRef]

31. Pereira, A.C.; Dinis-Carvalho, J.; Alves, A.C.; Arezes, P. How Industry 4.0 can enhance Lean practices. FME Trans. 2019, 47, 810-822. [CrossRef]

32. Pagliosa, M.; Tortorella, G.; Ferreira, J.C.E. Industry 4.0 and Lean Manufacturing: A systematic literature review and future research directions. J. Manuf. Technol. Manag. 2019, 32, 543-569. [CrossRef]

33. Taghavi, V.; Beauregard, Y. The Relationship between Lean and Industry 4.0: Literature Review. In Proceedings of the North American Conference on Industrial Engineering and Operations Management, Detroit, MI, USA, 10-14 August 2020; pp. 808-820.

34. Esmaeilian, B.; Sarkis, J.; Lewis, K.; Behdad, S. Blockchain for the future of sustainable supply chain management in Industry 4.0 Resour. Conserv. Recycl. 2020, 163, 105064. [CrossRef]

35. Lagorio, A.; Zenezini, G.; Mangano, G.; Pinto, R. A systematic literature review of innovative technologies adopted in logistics management. Int. J. Logist. Res. Appl. 2020. [CrossRef]

36. Tortorella, G.L.; Giglio, R.; van Dun, D.H. Industry 4.0 adoption as a moderator of the impact of lean production practices on operational performance improvement. Int. J. Oper. Prod. Manag. 2019, 39, 860-886. [CrossRef]

37. Feng, Q.; Shanthikumar, J.G. How Research in Production and Operations Management May Evolve in the Era of Big Data. Prod. Oper. Manag. 2018, 27, 1670-1684. Available online: https://onlinelibrary.wiley.com/doi/full/10.1111/poms.12836 (accessed on 19 July 2021). [CrossRef]

38. Basu, S.; Andrews, J.; Kishore, S.; Panjabi, R.; Stuckler, D. Comparative Performance of Private and Public Healthcare Systems in Low- and Middle-Income Countries: A Systematic Review. PLoS Med. 2012, 9, 19. [CrossRef]

39. Núñez-Merino, M.; Maqueira-Marín, J.M.; Moyano-Fuentes, J.; Martínez-Jurado, P.J. Information and digital technologies of Industry 4.0 and Lean supply chain management: A systematic literature review. Int. J. Prod. Res. 2020, 58, 5034-5061. [CrossRef]

40. Chehbi-Gamoura, S.; Derrouiche, R.; Damand, D.; Barth, M. Insights from big Data Analytics in supply chain management: An all-inclusive literature review using the SCOR model. Prod. Plan. Control 2020, 31, 355-382. [CrossRef]

41. Aryal, A.; Liao, Y.; Nattuthurai, P.; Li, B. The Emerging Big Data Analytics and IoT in Supply Chain Management: A Systematic Review; Supply Chain Management; Emerald Group Holdings Ltd.: Bingley, UK, 2020; Volume 25, pp. 141-156.

42. Pournader, M.; Shi, Y.; Seuring, S.; Koh, S.C.L. Blockchain applications in supply chains, transport and logistics: A systematic review of the literature. Int. J. Prod. Res. 2019, 58, 2063-2081. [CrossRef]

43. Seyedghorban, Z.; Tahernejad, H.; Meriton, R.; Graham, G. Supply chain digitalization: Past, present and future. Prod. Plan. Control 2019, 31, 96-114. [CrossRef]

44. Tranfield, D.; Denyer, D.; Smart, P. Towards a Methodology for Developing Evidence-Informed Management Knowledge by Means of Systematic Review. Br. J. Manag. 2003, 14, 207-222. [CrossRef]

45. Lamba a, K.; Singh, S.P. Big data in operations and supply chain management: Current trends and future perspectives. Prod. Plan. Control 2017, 28, 877-890. [CrossRef]

46. Mishra, D.; Gunasekaran, A.; Papadopoulos, T.; Childe, S.J. Big Data and supply chain management: A review and bibliometric analysis. Ann. Oper. Res. 2016, 270, 313-336. [CrossRef]

47. Bag, S.; Pretorius, J.H.C. Relationships between industry 4.0, sustainable manufacturing and circular economy: Proposal of a research framework. Int. J. Organ. Anal. 2020. [CrossRef]

48. Jabbour, C.J.C.; Fiorini, P.D.C.; Ndubisi, N.O.; Queiroz, M.M.; Piato, É.L. Digitally-enabled sustainable supply chains in the 21st century: A review and a research agenda. Sci. Total Environ. 2020, 725, 138177. [CrossRef]

49. Chang, S.E.; Chen, Y. When blockchain meets supply chain: A systematic literature review on current development and potential applications. IEEE Access 2020, 8, 62478-62494. [CrossRef]

50. Gallo, T.; Cagnetti, C.; Silvestri, C.; Ruggieri, A. Industry 4.0 tools in lean production: A systematic literature review. Procedia Comput. Sci. 2021, 180, 394-403. [CrossRef]

51. Queiroz, M.M.; Pereira, S.C.F.; Telles, R.; Machado, M.C. Industry 4.0 and digital supply chain capabilities: A framework for understanding digitalisation challenges and opportunities. Benchmarking 2019, 28, 1761-1782. [CrossRef]

52. Ghadge, A.; Kara, M.E.; Moradlou, H.; Goswami, M. The impact of Industry 4.0 implementation on supply chains. J. Manuf. Technol. Manag. 2020, 31, 669-686. [CrossRef]

53. Haddud, A.; Khare, A. Digitalizing supply chains potential benefits and impact on lean operations. Int. J. Lean Six Sigma 2020, 11, 731-765. [CrossRef]

54. Makris, D.; Hansen, Z.N.L.; Khan, O. Adapting to supply chain 4.0: An explorative study of multinational companies. Supply Chain Forum 2019, 20, 116-131. [CrossRef] 
55. Winkelhaus, S.; Grosse, E.H. Logistics 4.0: A Systematic Review towards a New Logistics System; International Journal of Production Research; Taylor and Francis Ltd.: Abingdon, UK, 2020; Volume 58, pp. 18-43.

56. Birkel, H.S.; Hartmann, E. Impact of IoT challenges and risks for SCM. Supply Chain Manag. Int. J. 2019, 24, 39-61. [CrossRef]

57. Arunachalam, D.; Kumar, N.; Kawalek, J.P. Understanding big data analytics capabilities in supply chain management: Unravelling the issues, challenges and implications for practice. Transp. Res. Part. E Logist. Transp. Rev. 2018, 114, 416-436. [CrossRef]

58. Wohlin, C. Guidelines for Snowballing in Systematic Literature Studies and a Replication in Software Engineering. In Proceedings of the 18th International Conference on Evaluation and Assessment in Software Engineering-EASE '14, London, UK, 13-14 May 2014. [CrossRef]

59. Kisperska-Moroñ, D. Responsibilities for inventory decisions in Polish manufacturing companies. Int. J. Prod. Econ. 2003, 81-82, 129-139. [CrossRef]

60. Giménez, C.; Lourenço, H.R. E-SCM: Internet's impact on supply chain processes. Int. J. Logist. Manag. 2008, 19, 309-343. [CrossRef]

61. Sanders, A.; Elangeswaran, C.; Wulfsberg, J.P. Industry 4.0 implies lean manufacturing: Research activities in industry 4.0 function as enablers for lean manufacturing. J. Ind. Eng. Manag. 2016, 9, 811-833. Available online: https://www.econstor.eu/ handle/10419/188791 (accessed on 27 September 2021). [CrossRef]

62. Kouhizadeh, M.; Saberi, S.; Sarkis, J. Blockchain technology and the sustainable supply chain: Theoretically exploring adoption barriers. Int. J. Prod. Econ. 2021, 231, 107831. [CrossRef]

63. Helo, P.; Shamsuzzoha, A.H.M. Real-time supply chain-A blockchain architecture for project deliveries. Robot. Comput. Manuf. 2020, 63, 101909. [CrossRef]

64. Kotzab, H.; Seuring, S.; Müller, M.; Reiner, G. Research Methodologies in Supply Chain Management; Physica-Verlag: Heidelberg, Germany, 2006; Available online: https://books.google.com/books?hl=en\&lr=\&id=LnGJJbImqngC\&oi=fnd\&pg=PR5\&dq= research+methodologies+in+supply+chain+management\&ots=da_WJcK_3c\&sig=154i-bBF6mBzsjWv1F77yl8Ae_A (accessed on 23 July 2021).

65. Novais, L.; Maqueira, J.M.; Ortiz-Bas, Á. A systematic literature review of cloud computing use in supply chain integration. Comput. Ind. Eng. 2019, 129, 296-314. [CrossRef]

66. Bruque-Cámara, S.; Moyano-Fuentes, J.; Maqueira-Marín, J.M. Supply chain integration through community cloud: Effects on operational performance. J. Purch. Supply Manag. 2016, 22, 141-153. [CrossRef]

67. Raji, I.O.; Rossi, T. Exploring Industry 4.0 technologies as drivers of Lean and Agile Supply Chain Strategies. In Proceedings of the International Conference on Industrial Engineering and Operations Management, Toronto, ON, Canada, 23-25 October 2019; Available online: http:/ / ieomsociety.org/toronto2019/papers/77.pdf (accessed on 29 June 2021).

68. Queiroz, M.M.; Telles, R.; Bonilla, S.H. Blockchain and Supply Chain Management Integration: A Systematic Review of the Literature; Supply Chain Management; Emerald Group Publishing Ltd.: Bingley, UK, 2019; Volume 25, pp. 241-254.

69. Jede, A.; Teuteberg, F. Integrating Cloud Computing in Supply Chain Processes: A Comprehensive Literature Review; Journal of Enterprise Information Management; Emerald Group Publishing Ltd.: Bingley, UK, 2015; Volume 28, pp. 872-904.

70. Shee, H.; Miah, S.J.; Fairfield, L.; Pujawan, N. The impact of cloud-enabled process integration on supply chain performance and firm sustainability: The moderating role of top management. Supply Chain Manag. Int. J. 2018, 23, 500-5177. [CrossRef]

71. Torres, B.; Naghshineh, B.; Cardeal, G.; Filipe, D.; Carvalho, H.; Peças, P.; Ribeiro, I. The Impacts of Additive Manufacturing Technology on Lean/Green Supply Chain Management Practices. Eur. Lean Educ. Conf. 2020, 122, 159-168. [CrossRef]

72. Tiwari, S.; Wee, H.M.; Daryanto, Y. Big data analytics in supply chain management between 2010 and 2016: Insights to industries Comput. Ind. Eng. 2018, 115, 319-330. [CrossRef]

73. Yong, B.; Shen, J.; Liu, X.; Li, F.; Chen, H.; Zhou, Q. An intelligent blockchain-based system for safe vaccine supply and supervision. Int. J. Inf. Manag. 2020, 52, 102024. [CrossRef]

74. Jain, G.; Singh, H.; Chaturvedi, K.R.; Rakesh, S. Blockchain in logistics industry: In fizz customer trust or not. J. Enterp. Inf. Manag. 2020, 33, 541-558. [CrossRef]

75. Zanoni, S.; Ashourpour, M.; Bacchetti, A.; Zanardini, M.; Perona, M. Supply chain implications of additive manufacturing: A holistic synopsis through a collection of case studies. Int. J. Adv. Manuf. Technol. 2019, 102, 3325-3340. [CrossRef]

76. Haddud, A.; Khare, A. The Impact of Digitizing Supply Chains on Lean Operations. In Marktorientiertes Produkt- und Produktionsmanagement in Digitalen Umwelten; Springer: Berlin/Heidelberg, Germany, 2018; pp. 27-46. [CrossRef]

77. Venkatesh, V.G.; Kang, K.; Wang, B.; Zhong, R.Y.; Zhang, A. System architecture for blockchain based transparency of supply chain social sustainability. Robot. Comput. Integr. Manuf. 2020, 63, 101896. [CrossRef]

78. De Giovanni, P. Blockchain and smart contracts in supply chain management: A game theoretic model. Int. J. Prod. Econ. 2020, 228, 107855. [CrossRef]

79. Dombrowski, U.; Richter, T.; Krenkel, P. Interdependencies of Industrie 4.0 \& Lean Production Systems: A Use Cases Analysis. Procedia Manuf. 2017, 11, 1061-1068.

80. Groten, M.; Gallego-García, S. A Systematic Improvement Model to Optimize Production Systems within Industry 4.0 Environments: A Simulation Case Study. Appl. Sci. 2021, 11, 11112. [CrossRef] 